ISSN 1518-3483

Licenciado sob uma Licença Creative Commons

\title{
A educação infantil e seu cotidiano
}

\author{
Preschool education and its daily life
}

\section{Elaine Maria Salies Landell de Moura ${ }^{[a]}$, Paulo Alexandre Cordeiro Vasconcelos ${ }^{[b]}$ \\ [a] Pedagoga, Mestranda em Educação, professora de Didática e Metodologia da Educação Infantil na Universidade Anhembi Morumbi, São Paulo, SP - Brasil, e-mail: emoura@broadneeds.com.br \\ [b] Docente em Educação, professor da Universidade Anhembi Morumbi, São Paulo, SP - Brasil, e-mail: paulovas@gmail.com}

\section{Resumo}

Inúmeras pesquisas no campo das neurociências cognitivas e da estimulação precoce demonstram a importância do trabalho cognitivo, psicomotor e afetivo que pode ser desenvolvido com crianças de 0 a 5 anos. Observa-se, nessas pesquisas, como é significativa a diferença de habilidades e competências entre crianças que tiveram estímulos adequados nesta fase, quando comparadas com as que não tiveram. Assim, espera-se que cada vez mais cresça o número de crianças de 0 a 5 anos na escola. O presente artigo discute a criança e seu desenvolvimento, destacando o cotidiano da educação infantil e a pedagogia de projetos para o desenvolvimento de um processo educacional interativo, que permita à criança atingir um grau de autonomia ao realizar escolhas e tomar decisões, ou pelo menos se aproximar dele.

Palavras-chave: Desenvolvimento infantil. Educação infantil. Projeto pedagógico. 


\section{Abstract}

Innumerable researches in the field of cognitive neurosciences and early stimulation demonstrate the importance of the cognitive, psychomotor and affective work that can be developed with children from 0 to 5 years of age. In these researches it is possible to observe how significant the difference of skills and competences between children that have had adequate stimulus in this stage is when compared with those who have not had it. Thus, the number of school children from 0 to 5 years of age is expected to grow continuously. The present article discusses the child and its development and highlights the daily life of preschool education and the pedagogy of projects aimed at the development of an interactive educational process that will enable the child to reach a degree of autonomy when making choices and decisions, or at least, approach it.

Keywords: Child development. Preschool education. Pedagogic project.

\section{Introdução}

Antigamente as crianças eram, na maioria dos casos, criadas pelas mães, irmãos mais velhos, vizinhos ou avós. Atualmente, nas cidades, cuidar de crianças tornou-se difícil, pois os espaços nas moradias são cada vez mais reduzidos, as ruas estão mais perigosas e as famílias ocupadas na garantia da sobrevivência, e, assim, fez necessário construir espaços próprios para a educação.

Simultaneamente, o desenvolvimento da ciência moderna e da tecnologia nos fez conhecer mais profundamente as crianças. A psicologia nos mostrou como o ser humano aprende e se desenvolve, a antropologia e a sociologia nos ajudaram a compreender as diferenças entre as crianças de diversos lugares, a pedagogia se voltou para a criação de processos educativos e para a construção de ambientes que ajudem no seu desenvolvimento.

Nesse contexto, as instituições de atendimento e de educação das crianças pequenas são vistas como uma complementação da ação da família, como realizadoras dos direitos das famílias, das mulheres e das 
próprias crianças e como exigência da vida social. Mas, diferente da estrutura familiar, a escola necessita estar estruturada para trabalhar eficientemente com essas crianças.

Uma das possibilidades de trabalho na educação das crianças pequenas é o desenvolvimento de projetos, pois a vida dos seres humanos é constituída por uma constante elaboração e reelaboração de planos. Afinal, antecipar é uma das importantes características da nossa espécie.

Boutinet (2002, p. 180) afirma que "uma das razões que encorajam a pedagogia de projetos vem da necessidade de quebrar o quadro coercitivo dos programas escolares para suscitar certa criatividade".

As propostas teóricas e metodológicas emanadas da escola nova não eram, certamente, unânimes em relação às alternativas pedagógicas, mas onde se constituíam tinham como objetivo a construção de uma visão crítica à educação convencional.

Nessa perspectiva, o trabalho com projetos reflete o pensamento de uma escola ativa, em que as crianças aprendem, sobretudo, ao partilhar diferentes experiências de trabalho em comunidade. Nesse contexto, a sala de aula, em especial na educação infantil, funciona como uma comunidade em miniatura, preparando seus participantes para a vida adulta.

Atualmente, ao falar de projetos é necessário incluir o contexto sócio-histórico, e não apenas o ambiente imediato, o conhecimento das características dos grupos de alunos envolvidos, a atenção à diversidade e o enfoque em temáticas contemporâneas e pertinentes à vida das crianças.

Assim, é necessário introduzir na escola de educação infantil um currículo interdisciplinar ou transdisciplinar, como afirmaria Morin (2001), para a religação dos saberes.

\section{A criança na educação infantil}

A criança que ingressa numa instituição de ensino tem a possibilidade de ampliar seu universo social e cultural, uma vez que passará a conviver com outras crianças e pessoas que não fazem parte do seu 
círculo familiar. Consequentemente, ela terá a oportunidade de conhecer outros hábitos, brincadeiras, costumes etc.

$\mathrm{Na}$ medida em que esse novo convívio social é construído, a criança da educação infantil irá perceber-se diferente dos colegas, e essa observação tem grande impacto na formação de sua personalidade e de sua autoestima, já que sua identidade está em construção. Nesse processo ela vai, gradualmente, percebendo-se e, ao mesmo tempo, percebendo os outros.

Segundo Vygotsky (2000), a relação homem-mundo é mediada por sistemas simbólicos, as funções psicológicas têm um suporte biológico, pois são produtos da atividade cerebral, e o funcionamento psicológico fundamenta-se nas relações sociais entre o indivíduo e o mundo exterior, as quais se desenvolvem num processo histórico.

Portanto, para que a criança se desenvolva é necessário que haja a interação e a troca com o outro, pois desta forma ela estabelece vínculos, cria regras e saberes e, para tal, utiliza-se de vários recursos, como a imitação, o faz de conta, a oposição, as diferentes formas de linguagens e outros.

Outra questão muito importante para a educação infantil é o brincar, fundamental para o desenvolvimento da identidade e autonomia da criança, já que por meio das brincadeiras a criança desenvolve algumas habilidades importantes, como, por exemplo, a atenção, a imaginação, a memória etc. Além disso, a brincadeira favorece a socialização por meio da interação e da utilização de regras e papéis sociais assumidos pela criança, sobretudo, nos jogos de faz de conta.

O educador pode observar, durante a brincadeira, quais recursos da memória a criança utiliza para assumir determinado papel e/ou função e, desta forma, pode perceber quais conhecimentos prévios ela utiliza para representá-los.

Quando a criança utiliza-se da linguagem do faz de conta, ela enriquece sua identidade, porque pode experimentar outras formas de ser e pensar, ampliando suas concepções sobre as pessoas e coisas que a cercam. 
Segundo Kishimoto (2002), o jogo é uma aquisição social, não é inato; por esta razão, o professor deve ensinar a criança a utilizar um brinquedo para que ela possa explorá-lo em sua totalidade.

Durante as brincadeiras, as crianças vivem um turbilhão de emoções e sentimentos - dependendo dos papéis que assumem -, que podem ser internalizados, auxiliando no desenvolvimento de um sentido próprio de moral e de justiça.

Na educação infantil, é possível observar esta prática, bastante comum, durante a disputa por um brinquedo, por exemplo. Embora esses momentos de conflitos sejam difíceis de administrar, é fundamental que eles ocorram, pois desempenham um papel importante na diferenciação e na afirmação do eu que refletirão na sua vida adulta.

Se na escola a criança é vista como um ser que deve ser apenas disciplinado para a aquisição de conhecimentos, o jogo não é aceito, mas marginalizado, em função da visão que o adulto tem da criança e da educação infantil.

Conforme Kishimoto (2002), o jogo deve ser valorizado por seu potencial para o aprendizado moral, para a integração da criança no grupo social e como meio para a aquisição de regras. Contudo, embora exista um estreito vínculo entre o jogo e o trabalho escolar, a educação deve, em certos momentos, separá-los, pois não se pode pensar em uma educação exclusivamente baseada em jogos, uma vez que essa postura isolaria o ser da vida, fazendo-o viver num mundo ilusório.

Além do faz de conta, das atividades lúdicas e dos jogos simbólicos, há também outro fator de grande relevância para a interação da criança: a linguagem.

A linguagem verbal é considerada um forte veículo de socialização, pois favorece o processo de diferenciação - eu e o outro - e, ao mesmo tempo, enriquece as possibilidades de comunicação e expressão. A criança é inserida no mundo da fala e da escrita desde o seu nascimento, ela é, portanto, um ser social rodeado de informações que lhes são transmitidas por meio da língua materna, com suas estruturas, conteúdos e construções, que vão de uma frase carinhosa - na interação entre pais e filhos até as histórias que compõem o repertório infantil. 
A riqueza nos estímulos da linguagem verbal e escrita, por meio de histórias, diálogos e textos diversos, favorecem um avanço no aprendizado da criança durante seu processo de construção do conhecimento.

Além da linguagem verbal e escrita, a linguagem corporal também possibilita à criança adquirir consciência dos limites do próprio corpo, diferenciando o eu do outro no processo de construção de sua identidade. Isso ocorre por meio das explorações pessoais, do contato físico com outras pessoas e da observação daqueles com quem convive.

O professor na educação infantil também deve elaborar atividades que favoreçam o exercício da cidadania, oferecendo aos alunos a oportunidade de escolha e autogoverno. A capacidade de realizar escolhas, tanto de materiais a serem usados quanto de atividades a serem realizadas, possibilita à criança tomar decisões, desenvolvendo o seu senso de responsabilidade.

Para que a criança atinja, ou pelo menos se aproxime desse nível de autonomia, é fundamental o papel do professor como aquele que organiza, sistematiza e conduz situações de aprendizagem. Sua ação como mediador das relações entre crianças e os diversos universos sociais nos quais interagem possibilita a criação de condições para que elas possam, gradativamente, desenvolver capacidades ligadas à tomada de decisões, à construção de regras, à cooperação, à solidariedade, ao diálogo, ao respeito a si mesmas e ao outro, assim como o desenvolvimento de sentimentos de justiça e ações de cuidado para consigo e para com os outros.

A pedagogia de projetos é uma excelente metodologia para tal, pois os projetos permitem um trabalho de forma interdisciplinar, abrangendo as diferentes áreas do conhecimento e percebendo as relações entre elas. Assim, o papel do professor é mediar e também acrescentar algo ao que é dado inicialmente, como forma de enriquecer o trabalho e suscitar discussões.

Partindo dos pressupostos descritos, passaremos a descrever o processo pelo qual a prática da pedagogia de projetos permitiu, em situações reais, a possibilidade de propiciar às crianças pequenas situações reais de aprendizagem. 


\section{Projetos na educação infantil}

"Por que não temos um animal de estimação aqui no colégio?"

"Os animais são seres vivos?"

Partindo destas indagações tão próprias em crianças de 4 e 5 anos da educação infantil, as professoras do Grupo 3 (G3) foram construindo o seu projeto pedagógico, desenvolvido no período de março a dezembro.

Como orientadora das professoras de educação infantil, pude acompanhar, detalhadamente, as descobertas do projeto "Conhecendo e ampliando horizontes", tendo como fio condutor "O que individualiza cada um de nós?".

Em um momento de roda, quando as professoras falavam dos diferentes animais de estimação, o grupo percebeu que a maioria já os tinha em casa. Ao discutir-se o assunto, surgiu a ideia de se ter um animal de estimação na escola, e foi quando uma criança fez a pergunta transcrita.

Percebendo o interesse da turma em trazer para o colégio um animal e sabendo que um dos objetivos da série era desenvolver a responsabilidade e o respeito ao próximo, as professoras do G3 elaboraram um projeto cujo tópico produtivo era "responsabilidade".

Dessa forma, iniciaram um projeto no qual trabalharam as diferentes áreas do conhecimento de modo sistêmico. Já que queriam que os alunos compreendessem os conhecimentos trabalhados, exploraram as principais perguntas que orientavam as investigações:

1) O que realmente queremos que nossos alunos compreendam?

2) Como é que nossos alunos compreendem?

3) Como sabemos que eles compreendem?

Após muitas reflexões, elaboraram os seguintes objetivos de compreensão para o projeto em questão:

1) os alunos deverão compreender que animais são seres vivos e, quando mantidos em cativeiro, requerem cuidados especiais para terem uma boa qualidade de vida; 
2) os alunos deverão compreender que é necessário agir com responsabilidade ao lidar com animais de estimação para mantêlos saudáveis.

Com os objetivos definidos e a turma sensibilizada, iniciaram a construção dos desempenhos de compreensão - pesquisa, busca de informações.

O trabalho foi construído e estruturado em conjunto com as crianças, conforme interesse delas e as leituras que as professoras realizavam - referencial teórico. Dessas leituras atentas sobre o conhecimento e das hipóteses levantadas pelas crianças foi estruturado um projeto didático que abordava o que elas sabiam e o que elas deveriam saber sobre "animais de estimação e sua qualidade de vida".

O primeiro passo foi a investigação dos possíveis animais que poderiam ter na escola. A partir das ideias das crianças, selecionaram-se textos diferentes, $\mathrm{CD}$, vídeos, livros e revistas, para a coleta das informações necessárias, o que culminou na decisão das crianças pela mascote que queriam ter no colégio. Acompanhei a busca de informações dos alunos para conhecer mais especificamente as necessidades sobre o animal escolhido para tê-lo no colégio e garantir sua sobrevivência.

Após muita discussão e seleção das informações, a turma passou a pensar de que maneira poderia divulgar para os colegas os conhecimentos que eles haviam adquirido sobre o animal e como divulgar tais informações para os outros de uma maneira criativa e de fácil compreensão. Com a ajuda das professoras, decidiram fazer uma apresentação oral, utilizando-se de figuras ilustrativas - um seminário.

Durante a apresentação do seminário pelas crianças, pude avaliar que estavam seguros ao explicarem para os colegas os conhecimentos apreendidos durante a pesquisa. Também comprovei que conseguiram expressar-se com clareza, argumentando sobre suas ideias. Constatei que todas estavam aptas a seguir com o projeto, colocando em prática tudo aquilo que havia sido descoberto em diferentes fontes e transformado em conhecimento. 
Ao acompanhar o desenvolvimento do projeto com as professoras, percebi que a língua materna estava muito presente nas discussões orais, nos diferentes textos utilizados nas pesquisas, nos registros individuais e coletivos, e que as docentes conseguiam usar de forma distinta os registros orais e os escritos.

Ferreiro e Teberosky (1999) afirmam que a construção do conhecimento da leitura e da escrita tem uma lógica individual, embora aberta à interação social, na escola ou fora dela. No processo, a criança passa por etapas, com avanços e recuos, até se apossar do código linguístico e dominá-lo.

O princípio de que o processo de conhecimento é gradual corresponde ao que Piaget (1977) chamou de assimilação e acomodação dos esquemas internos. É justamente por utilizar esses esquemas internos, e não simplesmente por repetir o que ouvem, que as crianças interpretam o ensino recebido. Portanto, o professor deve ter em mente que o que as crianças aprendem não coincide com o que lhes foi ensinado.

As artes se apresentavam nas constantes relações entre os desenhos, as pinturas, as fotografias, nas diferentes formas de comunicar algo, nas propostas artísticas dentro do projeto. Nesse sentido, Barbosa (1998) afirma que, ao designar os comportamentos do processo ensino-aprendizagem, três ações básicas se evidenciam mentalmente e sensorialmente: criação, leitura da obra de arte e contextualização.

Na matemática, diversas relações lógicas eram feitas a todo momento, aproveitando, principalmente, as situações do cotidiano, tanto no trabalho com jogos e brincadeiras, como aprofundando relações de classificação e seriação, noção de número e quantidade.

Nos jogos coletivos, de estratégias, cada criança trabalhou os seus conceitos, relacionando-os com os conceitos dos colegas, o que permitia uma reformulação e um crescimento nos seus conceitos.

O jogo, nas concepções de Rofatto (2010), é essencial para o desenvolvimento da criança, pois por meio dele ela aprende a socializar-se com os colegas, a vencer e a perder, a seguir regras. Além de promover interações, ações, reflexões, construção de hipóteses, troca e confronto de 
ideias, o jogo desenvolve o raciocínio lógico, a construção do conhecimento e a resolução de problemas.

E o brincar, o lúdico, tão importante na educação infantil? Nas brincadeiras livres foi possível perceber o que estava sendo forte no momento para cada uma das crianças na turma do G3: se era o que foi tratado em aula, se era uma situação familiar ou se era uma mudança de estrutura. Em diferentes momentos, revelava-se o que se tornava predominante.

Ao acompanhar o trabalho, pude perceber que as professoras do G3 mostraram como a discussão sobre a identidade evoluiu para um projeto longo e muito significativo, em que as crianças aprenderam sobre biologia, ciências, artes, linguagem, comunicação, afetividade, enfim, sobre as diferentes condições implicadas na escolha de uma mascote, um ser pelo qual assumiram responsabilidade.

\section{Algumas considerações}

O projeto não ficou restrito ao espaço físico da sala ou da escola, pois o conhecimento expandiu-se com a pesquisa sobre os dinossauros, a preservação e destruição da natureza, a sustentabilidade do planeta, o "acantonamento" e outros tantos conteúdos e vivências que foram surgindo desta turma de educação infantil.

Sem dúvida alguma, o trabalho com projetos foi muito envolvente e trouxe significados pessoais e coletivos para todos os que dele participaram sobre o conceito de responsabilidade.

Em relação aos professores, é necessário destacar dois aspectos importantes em relação a sua formação: primeiro, que o professor vai construindo suas próprias concepções sobre o ensino, tanto sobre a didática quanto ao seu comportamento em sala de aula, a disciplina, os próprios conteúdos; segundo, que é o professor quem decide sua forma de atuação em classe, quando ele está realmente implicado no processo. É fundamental que uma proposta pensada para a formação do professor considere o ponto de vista dos professores e suas particularidades. 
Uma das formas de dar conta dessas pedagogias diferenciadas e também da apropriação pela criança das diferentes linguagens é a pedagogia de projetos. Trabalhando com projetos, as crianças não "recebem conhecimentos" em pacotes, mas aprendem a partir de suas próprias hipóteses, sucessivamente, desestabilizadas e reformuladas. São, portanto, protagonistas do processo de ensino-aprendizagem.

\section{Referências}

BARBOSA, A. M. Tópicos utópicos. Belo Horizonte: CI Arte, 1998.

BOUTINET, J. P. Antropologia do projeto. Porto Alegre: Artmed, 2002.

FERREIRO, E.; TEBEROSKY, A. Psicogênese da língua escrita. Porto Alegre: Artmed, 1999.

KISHIMOTO, T. M. O jogo e a educação infantil. São Paulo: Pioneira Thomson Learning, 2002.

MORIN, E. Os sete saberes necessários à educação do futuro. São Paulo: Cortez; Brasília: UNESCO, 2001.

PIAGET, J. Psicologia da inteligência. Rio de Janeiro: Zahar, 1977.

ROFATTO, E. A. A brincadeira e os jogos: aportes para a construção do conhecimento. Disponível em: <http://sare.unianhanguera.edu.br/index.php/reduc/ article/viewFile/182/178>. Acesso em: 7 jun. 2010.

VYGOTSKY, L. S. A construção do pensamento e da linguagem. São Paulo: Martins Fontes, 2000.

Recebido: 18/09/2010

Received: 09/18/2010

Aprovado: 15/11/2010

Approved: 11/15/2010 